\title{
Study on Teaching College English Writing Based on Lexical Chunks
}

\author{
Linghui Gao ${ }^{1}$ \\ ${ }^{1}$ School of English Language, North China Electric Power University, Baoding, China \\ Correspondence: Linghui Gao, School of English Language, North China Electric Power University, Baoding, \\ China.
}

Received: June 3, 2019 Accepted: August 3, 2019 Online Published: August 5, 2019

doi: 10.5539/elt.v12n9p1 URL: https://doi.org/10.5539/elt.v12n9p1

\begin{abstract}
College English writing is one of the four basic skills in English learning, which can objectively reflect students' language ability. Whereas, English writing is considered to be the most difficult part to improve. As we can see, in the essays of the Chinese college students, there often appears Chinglish, correct in grammar but unauthentic in expression. In order to better the situation, the author has introduced the new idea of lexical chunks into the teaching of college English writing. Under this guideline, students should firstly understand the lexical chunks theory, ranging from the definition to the various classifications of lexical chunks. Afterwards, students should learn to recognize and even learn some important chunks by heart. The third step should lie in their daily practice of consciously using chunks they learned in their writings, followed by the final step of appropriate usage of chunks unconsciously. Students are expected to improve their writing ability in the process of identifying and using lexical chunks.
\end{abstract}

Keywords: college English writing, chunks, teaching steps

\section{Introduction}

\subsection{The Current Situation of College English Writing in China}

College English writing has long been in an embarrassing position in college English learning. Though it is not difficult for the Chinese teachers to understand what the students mean in their essays, it is rather confusing for the foreign teachers to fully know their meaning for the same essay. Chinglish in writing, the Chinese usage of English which is not common for native English speakers, has long been a problem and has become the bottleneck. In the author's two classes, it was found that the most obvious problem lies in the vagueness of expressions and the emergence of many Chinglish expressions.

Both teachers and students have poured a lot of time and energy to deal with this situation. It is not uncommon to see many students have bought all kinds of vocabulary books to enlarge their vocabulary, and some even try to recite the words in dictionary. Unfortunately, their effort has got little paid off and their English compositions are still far from perfect. Moreover, many chinses scholars also realized this phenomenon and published the relevant articles to analyze it from different angles. Qin (2017) studied the Chinglish phenomenon in Chinses-English translation, Shuai (2019) explored the reasons for Chinglish in writing from a psycholinguistics view.

\subsection{The Introduction of Lexical Chunks}

After a 3-year study and analysis, it seems to the author that the students often search single English equivalents of Chinese words, from either the books they newly learned or their minds, and then combine them mechanically piece by piece to construct a so-called English sentence. That is where the lexical chunk theory comes to the mind. As the same time, the author realizes some Chinese scholars have already realized the important role that the lexical chunks play in English learning and thus made some relevant research. For instance, Cao \& Zhang (2016) made an experimental study on improving students' translation competence based on lexical chunk. Zhou (2018) studied the impact of chunk teaching in college English to negative transfer of native language. Fei (2018) explored the impact of chunk teaching to college English writing. However, few scholars have made an elaborate analysis on how to apply chunk theory into the real classroom teaching activities. Therefore, based on Lewis's lexical approach, the author tries to teach English writing in college with the application of lexical chunks in order to find a practical way to improve English writing. 


\section{Definition and Classification of Lexical Chunks}

\subsection{Definition of Lexical Chunks}

The word "chunk" is often used as an umbrella term to refer to the multi-word combinations or units that are helpful in language acquisition, processing and use. The study of chunks can be traced back to 150 years ago when scholars began to realize the importance of multi-word combinations in child's language acquisition. However, no coherent term and definition have yet emerged. Different scholars use different and overlapping terms. Krashen (1978) uses semi-fixed patterns, Pawley and Syder (1983) prefers lexicalized sentence stems, Lewis (1993) applies lexical chunks, Wray(1999) puts it formulaic sequences, Moon (2002) uses multi-word items. Zhang (2018) steps a little further and uses multimodal lexical chunks. Although labeled differently, they mostly refer to the same phenomenon in language, that is, a sequence, continuous or discontinuous of words or other kinds of meaning elements which are stored and retrieved as a whole from memory. In this essay, the author opts for the term "lexical chunks".

\subsection{Classification of Lexical Chunks}

As noted earlier, there are many terms for chunks. So accordingly, different categories of chunks have been identified. And the most accepted and comprehensive ones are from Nattinger and DeCarrico, and Lewis.

Nattinger and DeCarrico (1992) put forward four large categories of lexical phrases based on four criteria: length and grammatical status; canonical or non-canonical shape; variability or fixedness; whether it is a continuous, unbroken string of words or discontinuous, allowing lexical insertions.

1) Poly-words are phrases that act as single words with no variability or lexical insertions, Examples include on the contrary, in a nutshell.

2) Institutionalized expressions refer to sentence-length, invariable, and mostly continuous expressions like, how do you do, nice to meet you, long time no see.

3) Phrasal constraints allow variations of lexical and phrase categories, and are mostly continuous. Phrases like $a$ day ago, long time ago, see you later, see you next time all fall into this category.

4) Sentence builders are those lexical phrases that allow the construction of full sentences with lots of variation and insertions, such as, I think that ..., my point is that ...

Michael Lewis also proposes four kinds of lexical chunks in his two works, the Lexical Approach (1993), Implementing the Lexical Approach (1997).

1) Words and Ploy-words: a single content word or the fixed phrases with a certain idiomatic quality, for example, school, ghost, by the way, rain cats and dogs.

2) Collocations: a combination of words in natural speech with a certain frequency, usually associate with verb-noun and adjective-noun phrases, such as, capital punishment, commit suicide.

3) Institutionalized Utterances: a combination of words, fixed or semi-fixed in form with more pragmatic function than referential meaning, such as, it has something to do with, it was not long before.

4) Sentence Frames and Heads: the structure mainly appears in written language to organize an essay, such as, it is generally acknowledged that...on the one hand, on the other hand.

As we can see, the above two categories have many overlapping parts though they may use different terms to mean it. Another thing the author should point out is about the first category by Lewis. According to the author, a single content words should be excluded from the chunk field for the reason that lexical chunks should mean the multi-word unit. Therefore, in this essay, the author classifies chunks into three categories with different emphasis and explanations by reference to the above classifications: collocations, institutionalized utterances, and sentence frame and heads.

\section{Lexical Chunks Teaching}

\subsection{Lewis' Teaching Approach}

In Lewis' two books, Lexical Approach, and Implementing the Lexical Approach: Putting Theory into Practice, he enthusiastically talks about how to apply lexical chunks to language teaching shown as follows.

1) Teachers should not analyze the target language at the very beginning, but will be more inclined to draw students' attention to these chunks.

2) In the process of language teaching, the importance of noticing and listening as well as the practice of repeating tasks are essentially emphasized. 
3) Translation and the speaking of the first language by teachers and students should not be totally avoided.

4) The traditional Present-Practice-Produce paradigm should be replaced by Observe-Hypothesis-Experiment cycle.

5) The main purpose of teaching activities introduced by teachers is receptive, awareness-raising of lexical chunks, rather than formal teaching in a high-anxiety learning atmosphere.

6) Besides the necessary learning aid such as a vocabulary notebook, more thoughtful, alphabetically indexed guidebooks with complete expressions, usage notes and other helpful information are also recommended.

Furthermore, Lewis put forward ten principles of classroom organization and several of them are listed as follows.

1) Topic. As for this part, the teachers must keep constantly aware of the different types of lexical items (chunks), which may be organized within a topic framework if necessary.

2) Situation. It stressed that sometimes physical situation can be the most useful way of organizing a bit of chunks.

3) Collocation. It functions as a central feature of a lexical view of language and identifying collocations is a primary pedagogical activity.

4) Notion. It means a synoptic description of an event with the psychological unity, for example, particular words or phrases may be used when comparing, analyzing or even reassuring.

5) Phonological chunking. It is strongly recommended that teachers should make full use of the intonation of formulaic speech for from psychological view, it is easier to remember a tune than a random sequence of notes.

6) Grammar. Grammar is given little attention, but not totally discarded.

Based on the above teaching guidelines, it is safe to make a conclusion that while highlighting the status of lexical chunks, equal attention should also be paid to the role of grammar and the natural psychological statue as well as the basic language skills of learners. That is to say, the chunk learning is not isolated and learners should have a relatively good command of English both in grammar and the four skills.

\subsection{Teaching Steps}

According to Lewis' Lexical Approach, the identification of lexical chunks should be placed in the first place. The second step goes to the organization or practice of chunks, followed by the final step of appropriate usage of chunks.

Recognition of chunks, especially for the beginners, is not an easy job. Therefore, some guidance is strongly recommended. Guided discovery by the teacher together with contextual guesswork by the students should be interchangeably adopted, which involves asking questions or offering examples that lead students to identify or guess the formation and meaning of chunks. Teachers can also use some techniques to facilitate their teaching process. In this way, students get involved in a process of semantic processing

After the successful identification of chunks, organization and practice will come in handy. In the early stages, teachers can organize some separate activities based on the three kinds respectively: collocations, institutionalized utterances and sentence frame and heads. In this process, teachers play the main role and should be prepared to give some prompt guide if necessary. After a certain period of time, students can make some practice by combining the four kinds together until they can write an essay skillfully.

Still, the relevant teaching activities should be undertaken in a light atmosphere rather than a high-anxiety learning atmosphere.

\section{Teaching English Writing by Lexical Chunks}

As stated before, a problem which puzzles the English writing in Chinse university is that the essays by the Chinese college students often appear peculiar and even inexact though grammatically correct. Therefore, a prevailing phenomenon is that foreign teachers will get lost when reading a composition by a Chinese. As a college English teacher, the author has always tried to adopt different methods to solve this problem but failed many times until the lexical chunk theory comes into view. So, after getting a relatively comprehensive understanding of lexical chunks, the author has tried to apply lexical chunks to teaching in order to find a new way to improve this situation. Take a classical essay writing Job Choice for example. The directions go like this, upon graduation, the fresh college graduates often are faced with two options to work in a state-owned company or to load a job in a joint venture. 


\subsection{The Arrangement of Outline in the Form of Lexical Chunks}

As the teacher, the author first explains macro-organizers (Qiu, 2009) in such a written discourse. As we all know, whether the essay is a formal one or an informal one, the basic outline should firstly be laid out. A clear layout will facilitate the understanding and thus get positive feedback from the readers or the viewers. Therefore, how to arrange the three paragraphs, namely, the opening, the body and the closing part, should be the first concern. The lexical chunks will hereby come in handy.

The chunks belonging to sentence frame and heads will help provide the framework for the essay. In paragraph one, the opening part of the essay, it usually starts like this: when it comes to the choice of ..., everyone has its own interpretation. In paragraph two, the body part of the essay, various reasons should be stated to explain the choice the writer made. The collocation chunks here can also play its role as the topic sentence, for instance, $A$ combination of factors will account for my choice, but generally speaking, they come down to the following three. Now we see a couple of collocations appear in one sentence: a combination of, account for, generally speaking, come down to. At the end of the essay, the closing part, the sentence frame like based on the above reasons, or some collocations like in conclusion, to sum up, to make a nutshell, etc will be quite suitable to be used to start the last paragraph.

Of course, for different topics, different chunks should be used. Only one or two chunks are far from enough. One the one hand, the teacher can make appropriate guide to help students accumulate as many chunks as possible in their daily study. One the other hand, the students should take the initiative to read more good essays and form a habit of writing down and memorizing the practical ones as much as possible and review them frequently. It is not an easy job especially at the early stage but it will definitely be a facilitator for the later studies.

\subsection{The Creation of Ideas in the Form of Lexical Chunks}

It is universally recognized that different angles should be stated to help illustrate the points and to make the argument more convincing. Quite a number of the students often use a lot of words to say only one point and their final scored will thus be affected because their narrow angles. As a teacher, the author will train students how to brainstorm the ideas step by step by using only several words or chunks to generalize one point and try to brainstorm as many points as possible.

As for this topic, suppose the choice is to work in a joint venture company, we can adpot chunks like competitive working atmosphere, well-paid job, a diverse business culture. These collocations will briefly state the different reasons for a specific choice.

\subsection{The Refinement of Details in the Form of Lexical Chunks}

Once the outline and the angles are fixed, another head-scratching part comes -how to polish the words. This part appears to be the most difficult part because of its diversity in different topics. It seems that the best strategy should be the frequent accumulation of daily expressions from various avenues such as from the materials from the social media such as the web, newspaper or magazine, everyday reading, communication with foreigners, and so on.

As for this topic, in the classroom teaching, the author firstly shows some relevant phrases in Chinese for the students to translate. During this process, students should think hard and also often commit various kinds of mistakes until finally know how to express the phrases authentically. Some chunks in the case may be adopted: bring the potential into full play, high salary, health problem, tend to, pay less attention to, posing an enormous threat to, to cover the daily expenses, pay the mortgage, broaden the horizon, enrich the life, expand the knowledge, and so on.

What is worth noticing is that, after class, students should review the chunks they have learned in class and try to learn some by heart. Only through consciously memorizing the often-used chunks, can learners finally recite them and perfectly use them unconsciously later.

\section{Summary}

The introduction and adoption of the lexical chunks is supposed to be a new angle in teaching college English writing, and we sincerely hope that it will offer a solution to the bottleneck problem existing in current English writing and provides an effective complement to the existing grammar vocabulary dichotomy.

\section{Acknowledgments}

This study is financially supported by the Fundamental Research Funds for the Central Universities (Grant NO. 2016MS136). 


\section{References}

Cao, F. L., \& Zhang, C. C. (2016). An Experimental Study on Improving Students' Translation Competence Based on Lexical Chunk. Computer-assisted Foreign Language Education, 170, 92-96.

Fei, Q., \& Li, L. F. (2018). The Impact of Chunk Teaching to College English Writing. Journal of Heilongjiang College of Education, 37(12), 151-153.

Krashen, S. D., \& Scarcella, R. (1978). On Routines and Patterns in Language Acquisition and Performance. Language Learning, 28(2), 283-300. https://doi.org/10.1111/j.1467-1770.1978.tb00135.x

Michael, L. (1993). The Lexical Approach: The State of ELT and the way Forward. Hove: Language Teaching Publication.

Michael, L. (1997). Implementing the Lexical Approach: Putting Theory in Practice. Hove: Language Teaching Publication.

Moon, R. (2002). Vocabulary Connections: Multi-words Items in English. Shanghai Foreign Language Education Press.

Nattinger \& Decarrico. (1992). Lexical Phrases and Language Teaching. Oxford: Oxford University Press.

Pawley, A., \& Syder, F. H. (1983). Two Puzzles for linguistic theory: native like selection and native like fluency. London: Longman.

Qin, L. L. (2017). A Study of Chinglish in Chinese-English Translation. Science and Technology Vision, 30, 65-66.

Qiu, R. L. (2009). An Application Study of Lexical Approach in College Students' English Writing (Master's thesis, Ocean University of China, Qingdao).

Shuai, T. (2019). The analysis of Chinglish under a Psycholinguistics View. Journal of Jilin Radio and TV University, 6, 105-106.

Wray. (1999). A Formulaic Language in Learners and Native Speakers. Language Teaching, 32, 213-231. https://oi.org/10.1017/S0261444800014154

Zhang, P. L. (2018). An Empirical Study of the Funcions of Multimodal Lexical Chunks in College English Teaching. Journal of Zhengzhou University of Light Industry (Social Science Edition), 19(3), 104-108.

Zhou, M. (2018). Study on the Impact of Chunk Teaching in College English to Negative Transfer of Native Language. Journal of Beijing Institute of Graphic Communication, 26, 129-131.

\section{Copyrights}

Copyright for this article is retained by the author(s), with first publication rights granted to the journal.

This is an open-access article distributed under the terms and conditions of the Creative Commons Attribution license (http://creativecommons.org/licenses/by/4.0/). 